\title{
THE RED EXPERIMENT \\ An Assessment of Boundary Layer Effects in a Trade Winds Regime on Microwave and Infrared Propagation over the Sea
}

\author{
by Kenneth Anderson, Barbara Brooks, Peter Caffrey, Antony Clarke, Leo Cohen, Katie Crahan, \\ Kenneth Davidson, Arie De Jong, Gerrit De Leeuw, Denis Dion, Stephen Doss-Hammel, \\ Paul Frederickson, Carl Friehe, Tihomir Hristov, Djamal Khelif, Marcel Moerman, \\ Jeffery S. Reid, Steven Reising, Michael Smith, Eric Terrill, and Dimitris Tsintikidis
}

The Rough Evaporation Duct experiment aimed to see if the effects of ocean waves account for errors in modeling the ranges at which radar and infrared can detect low-flying targets.

W hen radars first came into operation during the late 1930s, they were not expected to detect targets much beyond the geometrical horizon. These early radars, operating at a wavelength of $13 \mathrm{~m}$, generally met expectations. As new radars were rapidly developed, operating at shorter and shorter wavelengths for better target detection, observations of anomalous propagation effects became more frequent. When $10-\mathrm{cm}$ radars were installed along the south coast of England during World War II, they were often able to see the coast of France, even though the coast was well beyond the geometric horizon (Booker 1948). These anomalous propagation effects also became more pronounced as the operating area became more tropical. For example, a $1.5-\mathrm{m}-$ wavelength radar operating in Bombay, India, re-
AFFILIATIONS: ANDERSON, DOSS-HAMmEL, AND TSINTIKIDISAtmospheric Propagation Branch, Space and Naval Warfare Systems Center San Diego, San Diego, California; Brooks AND SMITH—School of the Environment, University of Leeds, Leeds, United Kingdom; CAFFREY - Remote Sensing Division, Naval Research Laboratory, Washington, DC; CLARKE-Department of Oceanography, University of Hawaii at Manoa, Honolulu, Hawaii; Cohen, De Jong, De LeEuW, AND MoERMAN-TNO Physics and Electronics Laboratory, The Hague, Netherlands; CRAHAN—Department of Atmospheric Sciences, University of Washington, Seattle, Washington; DAVIDSON AND FREDERICKSON-Department of Meteorology, Naval Postgraduate School, Monterey, California; DıON-Defense Research and Development Canada, Val-Belair, Quebec, Canada; FrIEHE AND KHELIF-Department of Mechanical Engineering, and Department of Earth System Science, University of California, Irvine, Irvine,
California; HRISTOV—Department of Earth and Planetary Sciences, John Hopkins University, Baltimore, Maryland; REID-Marine Meteorology Division, Naval Research Laboratory, Monterey, California; ReISING - Electrical and Computer Engineering Department, University of Massachusetts-Amherst, Amherst, Massachusetts; TERRILL-Scripps Institution of Oceanography, University of California, San Diego, La Jolla, California

CORRESPONDING AUTHOR: Kenneth D. Anderson, Space and Naval Warfare Systems Center San Diego, Atmospheric Propagation Branch, Code 2858, 53560 Hull St., San Diego, CA 92152

E-mail: kenneth.anderson@navy.mil

DOI:I0.II75/BAMS-85-9-1355

In final form 20 March 2004 
ported receiving echos from the coast of Africa some 1,700 miles away (Freehafer 1951a). By the end of World War II, it was clear that meteorology could be used to describe qualitatively, sometimes quantitatively, the observed anomalous propagation effects. In the years after the war, considerable effort was expended to develop and document theories, formulas, and experimental results relating to tropospheric effects on microwave (wavelengths from $1 \mathrm{~mm}$ to $1 \mathrm{~m}$ ) radio frequency propagation (Kerr 1951).

During World War II, Monin developed a theory (cf. Obukhov 1971) describing the vertical distribution of meteorological quantities within the surface layer (the layer adjacent to the earth's surface in which the surface influences the turbulent properties, typically extending from the surface to an altitude of some tens of meters). In the late 1960s, the MoninObukhov similarity (MOS) theory was experimentally confirmed over land (Businger et al. 1971) and was rapidly adapted to model microwave propagation over the sea (Jeske 1971). Although the earliest experimental work in microwave propagation over the sea was done in the late 1940s (Katzin et al. 1947), experimental work in the late 1960s and early 1970s (Jeske 1971; Richter and Hitney 1988) clearly identified a persistent meteorological phenomenon capable of confining, or ducting, microwave signals within the surface layer and propagating these signals to ranges well beyond the radio horizon. This meteorological phenomenon is called an evaporation duct because it is related to the rapid decrease in water vapor concentration in the first few meters above the sea surface. Although we focus on the evaporation duct, other meteorological conditions, such as a surface duct created by an elevated trapping layer (typically located at the top of the marine or internal boundary layers), may also significantly affect microwave and infrared (IR; wavelengths from $770 \mathrm{~nm}$ to $1 \mathrm{~mm}$ ) propagation. However, the scope of weather-related effects on propagation is beyond this paper; the reader is encouraged to explore the literature (e.g., Physical Society 1946; Bean and Dutton 1966; Hitney et al. 1985).

Electromagnetic (EM) signal propagation over a wind-roughened sea is strongly dependent on signal interaction with the sea surface, the mean profiles of pressure $(P)$, temperature $(T)$, humidity $(Q)$, wind $(U)$, and their turbulent fluctuations $(p, t, q, u)$. Yet within the marine surface layer these mechanisms are neither sufficiently understood for propagation, nor have satisfactory data been taken to validate propagation models, especially under conditions of high seas, high winds, and large surface gradients of $T$ and Q. The Rough Evaporation Duct (RED) experiment was designed to address this deficiency by providing data for the validation of meteorological and propagation models in the marine surface layer for rough surface conditions, including the effects of ocean waves.

In the surface layer over the ocean smooth-rough surface similarity theory is often applied to construct profiles of $T, Q$, and $U$. In this context, the rough boundary layer is derived from empirical relations where ocean wave characteristics are neglected (e.g., Fairall et al. 1996). For seas where wind speeds are less than $10-15 \mathrm{~m} \mathrm{~s}^{-1}$ there is excellent agreement for both meteorological and microwave propagation theory and measurements (cf. Hitney et al. 1985). However, recent evidence indicates that even small waves perturb $P, T, Q$, and $U$ profiles (hence, perturbing the evaporation duct) throughout the surface layer (Hristov et al. 1998, 2003). Indirect evidence of waveinduced distortion of these profiles is also indicated by analyses of earlier microwave signal propagation experiments (Anderson et al. 2003). It is, therefore, hypothesized that mechanical forcing by sea waves is responsible for modifying scalar profiles in the lowest portion of the surface layer, thereby reducing the effects of evaporation ducting. For high seas the duct is not as strong as the standard MOS theory predicts; hence, the received signal levels are less than expected. This hypothesis, that a rough sea surface modifies the evaporation duct, was the primary motivation for the RED experiment.

RED was conducted off of the Hawaiian Island of Oahu from late August to mid-September of 2001. The Scripps Institution of Oceanography Research Platform Floating Instrument Platform R/P FLIP, moored about $10 \mathrm{~km}$ off of the northeast coast of Oahu, hosted the primary meteorological sensor suites and the transmitters for both the microwave and the IR propagation links. In addition, two land sites were instrumented-one with microwave receivers and the other with an IR receiver-two buoys were deployed, a small boat was instrumented, and two aircraft flew various tracks to sense both the sea and atmospheric conditions (Fig. 1).

\section{METEOROLOGY AND PROPAGATION.}

Many processes affect the propagation of EM waves in the lower atmosphere. Within the horizon the dominant effect is spherical spreading. This process is characterized by the increasing surface area of a sphere centered on the transmitter and radiating outward; the power at any point is inversely proportional to the square of the distance between the transmitter and that point. Attenuation, or loss, due to spheri- 
cal spreading is known as free-space loss and is a commonly used reference in propagation. Refractive effects are those processes associated with the bending of EM waves and are related to the vertical pressure, temperature, and humidity distributions in the atmosphere. These effects are sometimes dramatic and can be the dominant propagation process within, near, and beyond the horizon. For EM terminals near the earth's surface, there may be several or more paths between the terminals. In addition to the direct path (through the atmosphere) the transmitted signal may be reflected toward the receiver by bouncing off of one or more surfaces, causing interference at the receiver. The magnitude of the interference depends on the reflection coefficient of the reflecting surface (related to the material and roughness of the surface) and the divergence of the reflected wave. Ocean waves roughen the sea surface but, for horizontally polarized microwaves, seawater is a very good reflector. For a fully developed sea the roughness is parameterized by a bump height given by $\sigma=$ $0.0051 U^{2}$, that modifies the smooth surface reflection coefficient by a factor of $e^{-\zeta}$, where $U$ is the wind speed $\left(\mathrm{m} \mathrm{s}^{-1}\right), \zeta=2[k \sigma \sin (\theta)]^{2}, k$ is the wavenumber, and $\theta$ is the angle of incidence at the surface (Phillips 1966; Ament 1953). Ducting is effective even in high seas. Diffraction around the earth's surface comes into play at ranges near and just beyond the horizon. Forward scatter from small-scale refractive heterogeneities in the atmosphere, a process known as troposcatter, becomes important at ranges far beyond the horizon. In addition to all of these processes, absorption by atmospheric gases and scattering by hydrometeors are sometimes significant effects.

The primary factors in signal propagation at IR are refraction, extinction, and scintillation. Scintillation is not a factor because 3-s averaging times were used for a measurement. A ray-trace analysis reveals that geometric refractive effects do not significantly perturb the propagation from the free-space inverse square law. This leaves extinction as the dominant factor in signal attenuation for IR wavelengths.

If the earth had no atmosphere, EM waves would travel in a line. From Snell's law, we know that the direction or curvature of a ray depends on its incidence angle and the refractive index $n$ of the medium. Near the earth's surface $n \cong 1.000350$ (for microwaves), so, for convenient numbers, we define refractivity as $N=(n-1) 10^{6}$; near the earth's surface $N \cong 350$. Atmospheric refraction may significantly affect received signal levels by causing changes to the direction of propagation, that is, the direction of the wave front normal (commonly called a ray). Signal

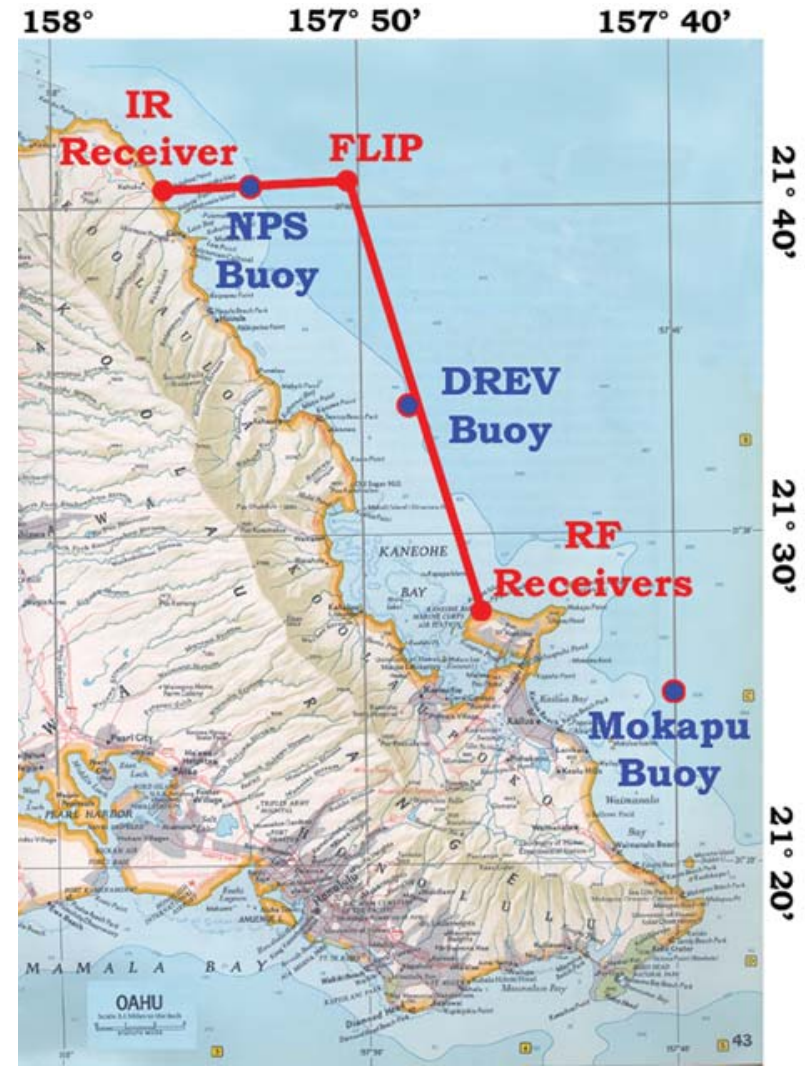

FIG. I. The geometry of the RED experiment. Oahu, HI, Aug-Sep $200 \mathrm{I}$.

energy may be refracted away from or focused toward the receiver, causing signal levels to decrease or increase with respect to an expected value. Microwave refractivity $N_{r}$ is related to atmospheric observables as

$$
N_{r}=77.6 \frac{P}{T}+\frac{3.73\left(10^{5} e\right)}{T^{2}},
$$

where $P$ is the pressure $(\mathrm{hPa}), e$ is the water vapor pressure (hPa), and $T$ is temperature $(\mathrm{K})$ of the air parcel (Bean and Dutton 1966); the units are $N$, which is dimensionless by its definition. Optical refractivity $N_{o}$ is dispersive; it is wavelength dependent. In the IR it is well approximated by

$$
N_{o}=\frac{P}{T}\left(77.6+\frac{0.584}{\lambda^{2}}\right),
$$

where $\lambda$ is the wavelength ( $\mu \mathrm{m}$; for greater detail see Edlen 1966). The most important feature for propagation prediction is the vertical gradients of refractivity. Taking the differential of (2) produces terms 
in both temperature and pressure, but the pressure terms are small and rapidly dispersed. Hence, in the IR, refractivity variations are a function of temperature variations only. In contrast with the IR case, the gradient in near-surface water vapor pressure is a dominant factor for microwave refractivity.

In propagation modeling the relative curvatures of the earth and the EM waves (or rays) is important. Modified refractivity $M$ is introduced to transform propagation calculations from real world cylindrical or spherical coordinates to Cartesian coordinates (Freehafer 1951b). Defining $M$ as $N+0.157 z$, where $z$ is the height in meters above the earth's surface, preserves the relative curvature, provided that the EM transmitters and receivers are within a few kilometers of the surface (Pekeris 1946). The vertical gradient of $M, d M / d z$, provides a useful tool. From its definition, when the gradient is 0 , a ray launched parallel to the earth's surface will propagate with the same curvature as the earth. This ray will remain parallel to the earth's surface as it propagates in range. When $d M /$ $d z$ is greater than 0 the ray will curve away from the earth's surface and when $d M / d z$ is negative the ray will curve toward the surface, decreasing in height with increasing range and eventually striking the earth's surface.

We classify atmospheric layers according to the vertical gradient of $M$. A subrefractive layer is defined as a layer where $d M / d z>157 \mathrm{M} \mathrm{km}^{-1}$. A normal layer is defined as $78<d M / d z \leq 157 \mathrm{M} \mathrm{km}^{-1}$. A superrefractive layer is defined as $0<d M / d z \leq 78 \mathrm{M} \mathrm{km}^{-1}$, and a trapping layer is defined as $d M / d z \leq 0$ (Hitney et al. 1985). For propagation near the earth's surface, we define a standard atmosphere where $d M / d z=$ $-118 \mathrm{M} \mathrm{km}^{-1}$, corresponding to a well-mixed, nonanomalous propagation medium. This description is often used in propagation as a reference for a benign environment.

\section{EXPERIMENT DESIGN AND MODELING.}

FLIP, shown in Fig. 2, was three-point moored in about $300 \mathrm{~m}$ of water with its keel aligned into trade winds that were typically from $080^{\circ}$ at about $7 \mathrm{~m} \mathrm{~s}^{-1}$. Its port boom, extending about $17 \mathrm{~m}$ from the hull in a northerly direction, was fitted with a vertical mast instrumented with sensors to measure $P, T, Q, U$, and their fluctuations (cf. Friehe and Hristov 2003; Hristov and Friehe 2003). Aerosol particle size and vertical distributions were measured (Reid et al. 2003; De Leeuw et al. 2003; Nilsson et al. 2003). Meteorological sensors were located on a flux buoy (Frederickson et al. 2003), positioned midway between FLIP and the shore along the westerly $10.4-\mathrm{km}$ path; additional meteo- rological sensors were located at the shore site (Clarke et al. 2003). The $T, Q, U$, and wave height were also observed on a mean met buoy, which was deployed by the Canadian Defense Research Establishment, Valcartier (DREV). This buoy was positioned midway on the southerly $25.7-\mathrm{km}$ microwave path. Meteorological and wave height data were also obtained from the University of Hawaii's buoy located near Mokapu Point (see Fig. 1). Two sets of three continuous wave microwave transmitters, radiating at 10 , 3 , and $1.5 \mathrm{~cm}$, were installed on the starboard side of FLIP at nominal heights of 5 and $13 \mathrm{~m}$ above the sea and were received at a site located $4.7 \pm 0.5 \mathrm{~m}$ above the sea on the Marine Corps Base Hawaii (MCBH; see Anderson et al. 2003 for details). Propagation of IR signals was measured using an IR transmissometer comprising a broad-beam source modulated by a $690-\mathrm{Hz}$ chopper wheel and receiver telescope coupled to a cooled midwave (3.5-4.1 $\mu \mathrm{m})$ IR detector. The source was mounted on FLIP at a height of $12 \mathrm{~m}$ above sea level. The receiver was installed at a shore site $10.4 \mathrm{~km}$ west of FLIP, at a height of $3 \mathrm{~m}$. The detector signal was separated from the chopped carrier waveform by means of a lock-in amplifier (details on the IR instrumentation are provided by Tsintikidis et al. 2003).

Two aircraft were available during RED—a Twin Otter from the Naval Postgraduate School (NPS) Center for Interdisciplinary Remotely Piloted Aircraft Studies (CIRPAS), and a Seneca from the University of Hawaii. The Twin Otter was instrumented with wind, temperature, humidity, IR sea surface temperature, aircraft motion, and navigation sensors. The response time of the relevant instruments was fast enough to resolve the smallest flux-carrying eddies (additional details are found in Khelif et al. 1999). The

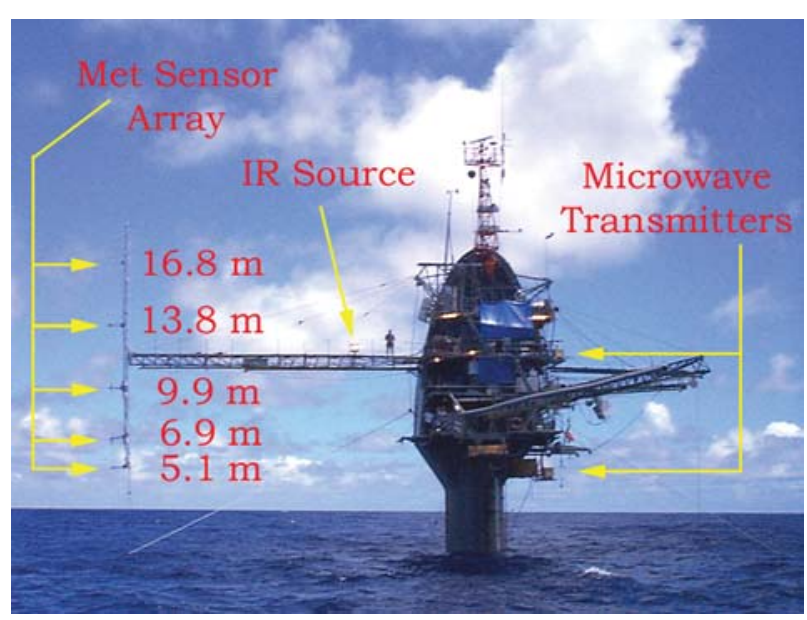

Fig. 2. R/P FLIP as moored for RED. 
aircraft was based at MCBH Kaneohe, and flew 14 flights from 22 August to 15 September 2001.

Modeling of microwave propagation loss, the signal attenuation between the transmitter and the receiver, is a two-step process. First, mean values (5-min averages) of sea temperature $T_{s}$, with values of $P, T$, $Q$, and $U$ measured at a reference height above the sea, are processed using the NPS bulk model (Frederickson et al. 2003) to estimate the vertical profiles of $P, T, Q$, and $e$ using MOS and hydrostatic formalism. The vertical refractivity profile $N_{r}$ is computed from these quantities via Eq. (1). In the second step, the $N_{r}$ profile and the surface bump height $\sigma$ are processed by the Advanced Propagation Model (APM) to estimate propagation loss for each frequency and link geometry. APM (Barrios 1992) uses the parabolic equation method (Levy 2000) to solve the Helmholtz wave equation in the 2D domain of range and height. It is capable of modeling propagation for EM wavelengths from $3 \mathrm{~mm}$ to $300 \mathrm{~m}$ with range- and height-varying vertical refractivity profiles over range- and height-varying surfaces of sea, land, or both. While APM can handle range-varying $N_{r}$ profiles and surface conditions, only one $N_{r}$ profile and one $\sigma$ value were used at a time to represent the entire $25.7-\mathrm{km}$ path. Attenuation due to atmospheric gases (Liebe 1985) was computed from the averaged meteorological observables, scaled by the range, and added to the APM-computed propagation loss. Temporal and spatial variations in range and height were included in the modeling. Tides at the shore sites varied about $\pm 0.5 \mathrm{~m}$. FLIP's position, monitored by GPS, varied about $\pm 100 \mathrm{~m}$ in range. The height of the sources mounted on FLIP increased $0.7 \mathrm{~m}$ during RED as FLIP consumed fuel, thus, rising out of the water.

Propagation modeling in the IR follows a similar process. The attenuation of the IR signal due to atmospheric gases is predicted by computing molecular scattering and absorption. This extinction factor depends on the IR wavelength, the gas $\left(\mathrm{N}_{2}, \mathrm{O}_{2}, \mathrm{CO}_{2}\right.$, $\mathrm{H}_{2} \mathrm{O}$, etc.), concentration, pressure, and temperature. The computer program, Moderate Resolution Transmittance Code (MODTRAN; Berk et al. 1999) was used to compute the transmittance (the ratio of the received intensity to the intensity expected in free space, $I / I_{o}$ ) for each meteorological data point. Aerosol extinction, the loss due to scattering and absorption by aerosol particles, depends on the IR wavelength, the aerosol type, particle size, and vertical distributions. Aerosol extinction was determined by using the Advanced Navy Aerosol Model (ANAM; van Eijk et al. 2002). Thus, a resultant transmittance due to aerosol extinction can be found, and the total trans-

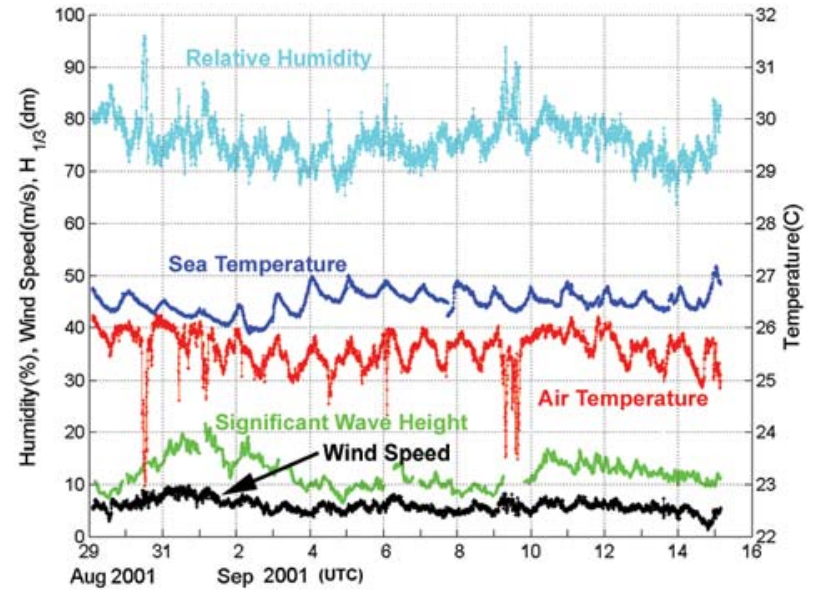

Fig. 3. Surface conditions as measured by the NPS buoy where the sensors are roughly $4 \mathrm{~m}$ above the sea. Relative humidity (cyan), significant wave height (green, decimeters), and wind speed (black) use the left scale, sea temperature (blue) and air temperature (red) use the right scale.

mittance is the product of the molecular and aerosol transmittance.

\section{MEASUREMENTS AND COMPARISONS} TO MODELED EFFECTS. Surface meteorology. Mean values of $P, T, Q$, and $U$ were measured at various levels aboard FLIP (Friehe and Hristov 2003), the NPS flux buoy (Frederickson et al. 2003), and the DREV mean met buoy. The general trade wind conditions resulted in a moderately unstable surface layer with an average air-sea temperature difference of about $-1^{\circ} \mathrm{C}$. Figure 3 shows air and sea temperature, relative humidity, significant wave height $(\mathrm{dm})$, and wind speed from the NPS buoy, which are representative of the measurements aboard both FLIP and the DREV buoy.

It is instructive to compare propagation effects in the IR to those in the microwave. At 0225 UTC 29 August 2001, the NPS buoy reported $U=5.5 \mathrm{~m} \mathrm{~s}^{-1}$, $T=26.23^{\circ} \mathrm{C}, T_{s}=26.77^{\circ} \mathrm{C}, \mathrm{RH}=80.2 \%$, and $P=$ $1014.1 \mathrm{hPa}$. Using MOS theory, the NPS bulk model constructs the vertical profiles of $T$ and $Q$ from these inputs as shown in Fig. 4, which are then transformed by Eqs. (1) and (2) to the vertical modified refractivity profiles shown in Fig. 5. The term evaporation duct height is defined as the height in the vertical profile, where $d M / d z=0$ and is a useful measure of the duct's ability to effectively trap microwave radiation. The $M_{r}$ profile in Fig. 5 has a trapping layer with an evaporation duct height of $10.6 \mathrm{~m}$. The $M_{o}$ profile monotonically increases, so its gradient is positive; this implies that for IR propagation the rays will curve upward. 

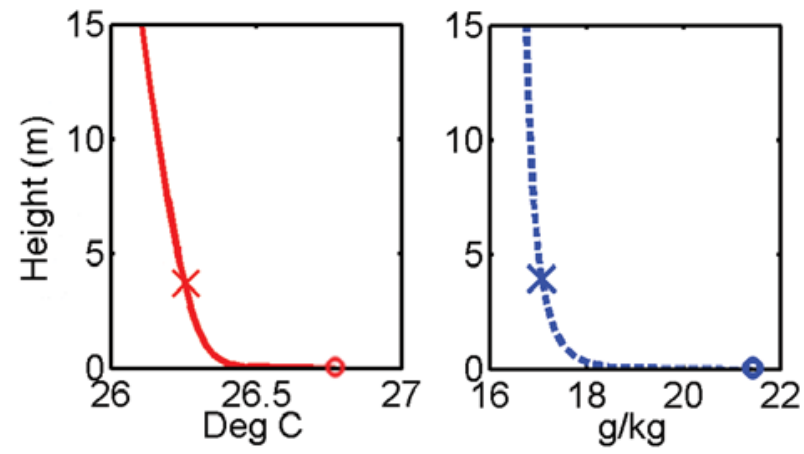

FIG. 4. The air temperature (red) and specific humidity (broken blue) profiles computed using MOS theory for bulk measurements where $U=5.5 \mathrm{~m} \mathrm{~s}^{-1}, T=26.23^{\circ} \mathrm{C}$, $T_{s}=26.77^{\circ} \mathrm{C}$, RH $=80.2 \%$, and $P=1014.1 \mathrm{hPa}$. The $X$ symbols indicate the measured values at $4 \mathrm{~m}$ above the surface.

Figure 6 shows a series of ray traces through the $M$ profiles of Fig. 5 . Here, the transmitter is located $5 \mathrm{~m}$ above the surface and a cone of rays is shown for $\pm 0.05^{\circ}$ from the horizontal. For microwave, the rays are trapped within the duct and propagate close to the surface. The IR rays appear to curve upward more at an increasing range, but this is mostly an artifact of the transformation to a flat earth and the effects induced by the $M$ profile. Ray tracing shows the direction of the energy flow; it is sometimes difficult or impossible to extract the magnitude of the signal along the ray.

EdgeTech Vigilant dewpointers and Hart precision thermistors were collocated in EG\&G 110SM aspirated and baffled housings at five levels aboard FLIP (Friehe and Hristov 2003). These data were sampled at $50 \mathrm{~Hz}$ (dewpoint) and $1 \mathrm{~Hz}$ (temperature), and were averaged over 30 -min periods together with

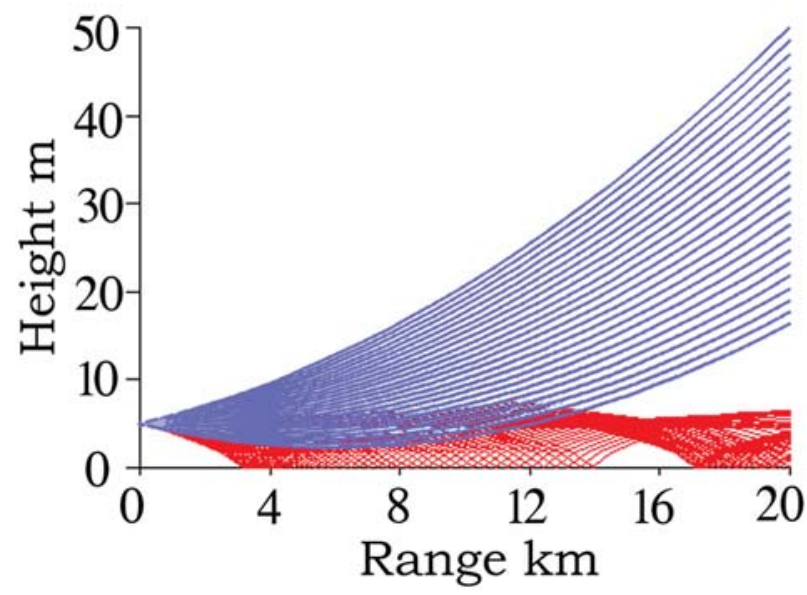

Fig. 6. A comparison of ray traces through the $M$ profiles, IR (blue) and microwave (red), of Fig. 5.

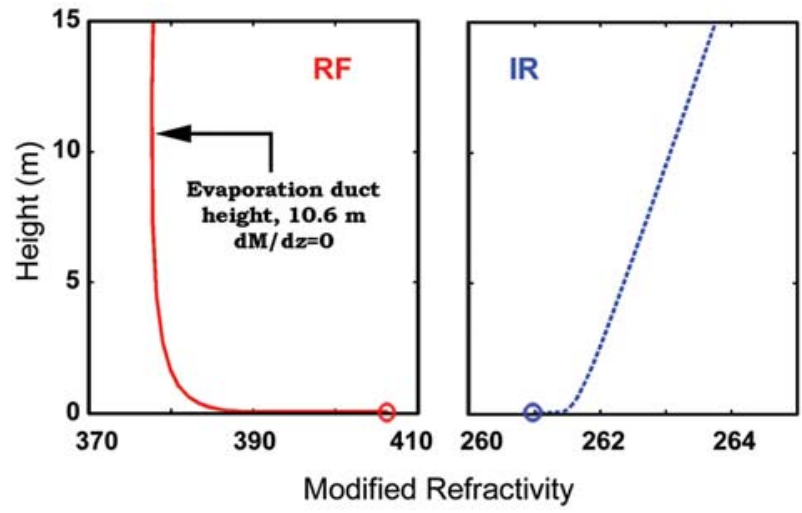

FIG. 5. The microwave- (red) and IR- (broken blue) modified refractivity profiles corresponding to the data in Fig. 3. The IR profile was constructed using a wavelength of $4 \mu \mathrm{m}$.

the fluxes. Figure 7 shows height profiles of potential temperature $\theta$ for two sample periods. (Only four heights are shown because the aspirating fan at the 9.9-m height failed early on in the experiment, causing temperature data contamination by solar radiation.) Each panel illustrates a 30-min average (heavy line) with 20 consecutive 1-s samples (light lines) as examples of the variability. The left panel is typical of the measurements; the average gradient $d \theta / d z$ is semilogarithmic. However, periods of time-averaged temperature profiles were sometimes found to not be monotonically decreasing with height above the sea, as shown in the right panel, representing a significant departure from MOS theory. Explanation of these anomalous gradients is the subject of an ongoing in-

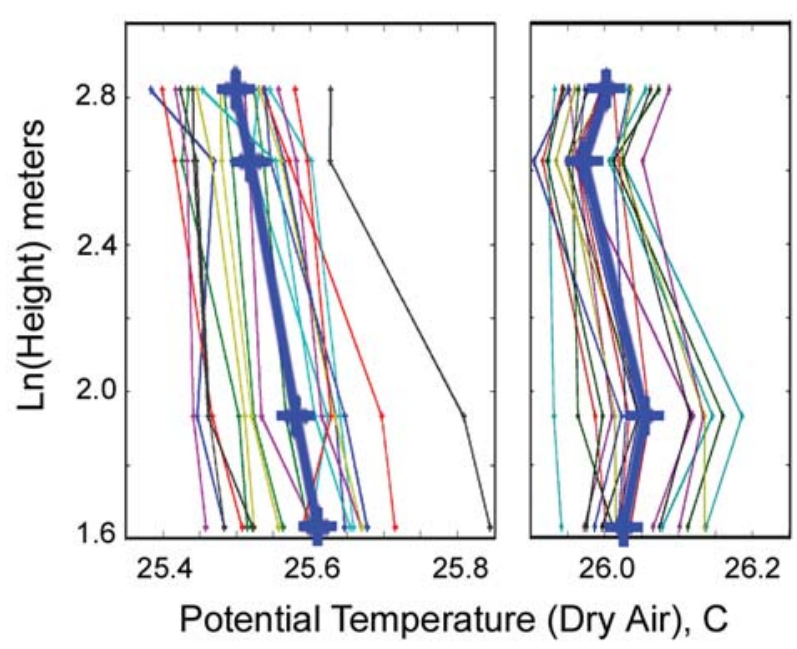

FIG. 7. Vertical profiles of potential temperature observed along the vertical mast of FLIP. The heavy blue line corresponds to a $30-\mathrm{min}$ average of I-s-sampled data. The lighter lines correspond to 20 consecutive I-s samples to illustrate the variability. 
vestigation. Instrumentation error does not seem to be the cause.

Accompanying measurements of momentum, heat, and water vapor fluxes were obtained on board FLIP so that profile functions, in the context of MOS theory, could be determined. The profile functions for temperature and moisture are related to the gradients as

$$
\frac{k z}{\theta_{*}} \frac{d \theta}{d z}=\phi_{h}\left(\frac{z}{L}\right)=\frac{1}{\alpha_{h}}\left(1-\gamma_{h} \frac{z}{L}\right)^{-1 / 2}
$$

for temperature, and

$$
\frac{k z}{q_{*}} \frac{d q}{d z}=\phi_{q}\left(\frac{z}{L}\right)=\frac{1}{\alpha_{q}}\left(1-\gamma_{q} \frac{z}{L}\right)^{-1 / 2}
$$

for moisture, where $k$ is the von Kármán constant $(k=0.40), z$ is the height in meters above the surface, $\theta$ is potential temperature, $\phi$ is the profile function (dependent on $z / L$ ), $\alpha$ and $\gamma$ are constants, $L$ is a stability scaling length, $q$ is the specific humidity, and the subscript $*$ indicates a scaling parameter (see Fairall et al. 1996; Businger et al. 1971; and Obukhov 1971).

Profile functions for temperature and humidity (derived from the 30-min-averaged FLIP measurements), shown in Fig. 8, agree with the one-half power of the stability term $(1-\gamma z / L)$, but have different constants than the profile functions measured over land (cf. Oncley et al. 1996); the gradients are larger over the ocean than over land. Future effort will be devoted to refining the profile function determinations and examining the conditions for deviations of the profiles from the semilog form.

Waves deform the mean wind streamlines and displace the sheared vertical profiles of temperature and humidity, thus leading to wave-induced fluctuations of refractivity. Figure 9 shows a time period of uncompensated scalar observations made during RED. From top to bottom, left to right, the panels show streamline wind velocity, vertical wind velocity, wave height, air temperature, humidity, and refractivity, all plotted with respect to wave phase. The green dashed line references a wave phase of $180^{\circ}$ (trough). It is likely that the different phase shifts shown (e.g., the streamline wind velocity is nearly $180^{\circ}$ out of phase with the waves, whereas the humidity is $90^{\circ}$ out of phase) are due to the uncompensated nature of these measurements. However, the periodicity with waves is clearly shown and is in good agreement with Miles' theory (Miles 1957; Hristov et al. 1998; Hristov et al. 2003).

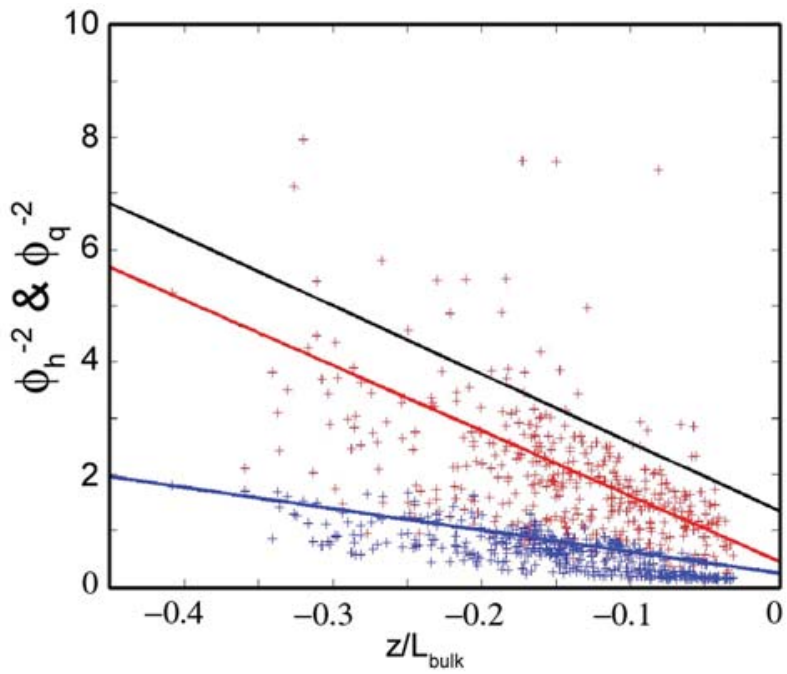

FIG. 8. Profile functions of temperature (red) and moisture (blue) during RED compared to the profile function of Oncley et al. (1996; black) as measured over land.
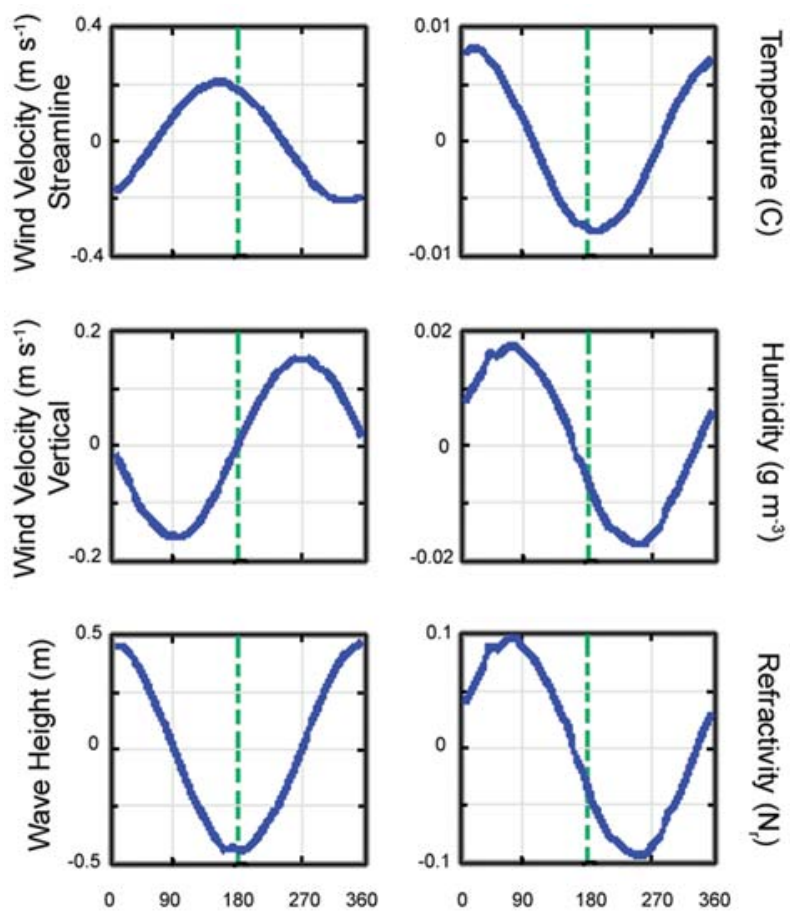

Wave Phase $\left({ }^{\circ}\right)$

FIG. 9. Streamline wind velocity, temperature, vertical wind velocity, humidity, wave height, and RF refractivity plotted versus wave phase.

The variation in refractivity $N_{r}$ (lower-right panel) is approximately $\pm 0.1 \mathrm{~N}$ units. This small variation in $N$ has little impact on the results from propagation modeling; any effect is buried in noise. If we had encountered higher winds and higher waves during RED, perhaps we could have seen a much larger varia- 
tion in $N$ and a corresponding measurable effect on propagation.

Radiosondes. A small boat (the Wailoa) was used to make kiteborne radiosonde profiles of pressure, temperature, and humidity from near the surface $(<1 \mathrm{~m})$ to the top of the surface layer (Davidson et al. 2003). Either a 4- or a 6-ft nylon delta kite was attached to a line that was deployed by a reel mounted on a fishing rod. A Vaisala RS-80 radiosonde, measuring values of temperature, pressure, and humidity approximately every $2 \mathrm{~s}$, was attached to the kite. By adjusting the reel drag, the kite and radiosonde were raised and lowered multiple times from near the surface to heights of $100 \mathrm{~m}$.

Figure 10 compares the MOS-derived temperature, specific humidity, and microwave-modified refractivity profiles to the profiles measured by the kiteborne radiosonde on 10 September 2001. The temperature profiles are offset, likely due to different temperature sensors, whereas the specific humidity and the microwave-modified refractivity profiles are in very good agreement. These direct measurements illustrate the power of MOS theory; using simple meteorological measurements at a reference height, MOS theory predicts vertical profiles that are quite similar to those observed.

Standard radiosondes were also taken at the $\mathrm{MCBH}$ Kaneohe airfield from 28 August through 14 September 2001. Modified refractivity gradients $d M_{r} / d z$ were linearly fit to an altitude interval of 50 $500 \mathrm{~m}$ and ranged from 117 to $143 \mathrm{M} \mathrm{km}^{-1}$, which is typical for normal atmosphere gradients (Hitney et al.
1985). No significant elevated trapping layers were observed in the data; these radiosondes confirmed that evaporation ducting was the dominant propagation mechanism.

Microwave and IR propagation. Figure 11 illustrates the comparison of observed and modeled propagation loss for the high- and low-sited 3-cm microwave links during RED. The reference line labeled free space corresponds to the propagation loss expected if the link paths were in free space, that is, a vacuum with no obstructions between the transmitters and receiver. The reference line labeled standard atmosphere corresponds to the propagation loss expected for atmospheric conditions of a well-mixed, nonanomalous troposphere. The observed signal levels (blue dots) are consistently near free space for the high transmitter and nearly always exceed free-space levels for the low transmitter. For the low transmitter, the effect of the evaporation duct is an increase in the received signal strength to levels greater than the level if the system were operating in free space. Compared to standard atmospheric predictions (the level indicated by the standard atmosphere reference line) evaporationducting effects on $3-\mathrm{cm}$ propagation increases the average received signal level by better than a factor of 100 for the high-sited transmitter and better than 1000 times for the low-sited transmitter. The maximum signal-level increase is better than a factor of 10 times the average increase. These significant increases in received signal level are provided by meteorology, for free!

The mean and standard deviation of the difference between the observed (blue dots) and modeled (red crosses) propagation loss is -0.2 and $4.0 \mathrm{~dB}$ for the high-sited transmitter and 4.3 and $3.4 \mathrm{~dB}$ for the low-sited transmitter. Similar results are found for comparisons at the other transmission wavelengths of 1.5 and $10 \mathrm{~cm}$ (Anderson et al. 2003). For propagation modeling, differences of a few decibels between the observations and model are considered quite good.

A comparison of the modeled IR transmittance and the measured transmittance over a $72-\mathrm{h}$ period is shown in Fig. 12. Received signal intensity is shown as a black line labeled $\tau$ (observed). The signal has been scaled to the free-space value 
(accounting for the inverse-square law attenuation of the mildly divergent beam), and it is apparent that the overall signal intensity is low.

Total extinction is the product of extinction due to molecules and aerosol. The MODTRAN program determines transmission due to molecular absorption and scattering, and that is shown in the figure as a green curve labeled $\tau$ (molec). Extinction due to aerosols is determined by the ANAM, and the total modeled extinction due to the combination of aerosols modeled by ANAM and gases (MODTRAN) is shown in blue as $\tau$ [aero(molec)]. A best-fit comparison shows the measured value to be $62 \%$ of the modeled prediction, with a cross correlation of 0.83 .

A second method of predicting aerosol extinction is to compute the Mie extinction factors directly from aerosol particle counts made on board FLIP at a height of $20 \mathrm{~m}$. The predicted transmittance deduced from the aerosol measurements combined with the gaseous extinction (from MODTRAN) is shown in red and is labeled $\tau$ (aero_obs)(molec). Because of substantial vertical gradients in aerosol concentration, the predicted transmission at a 20- $\mathrm{m}$ height is expected to be greater than transmission on the actual IR path between a source $12 \mathrm{~m}$ high and a receiver at a $3-\mathrm{m}$ height. However, the discrepancy between modeled and observed transmittance has not yet been resolved. Possible explanations are additional aerosol extinction from the surf zone or the very near surface path that the IR signal takes to the receiver (down to $1 \mathrm{~m}$; Clarke et al. 2003; Crahan et al. 2003). Investigation of these and other possible explanations is ongoing.

CONCLUDING REMARKS. The RED experiment was conducted off the Hawaiian Island of Oahu in late August to mid-September 2001. In addition to FLIP, two land sites were instrumented with microwave and IR receivers and meteorological sensors. Two buoys were deployed, a small boat was instrumented, and two aircraft flew various tracks to sense both sea and atmospheric conditions. Eleven scientists and engineers were aboard FLIP and installed instruments measuring mean and turbulent meteorological quantities, sea wave heights, flow direction, wave kinematics, upward and downward radiance,

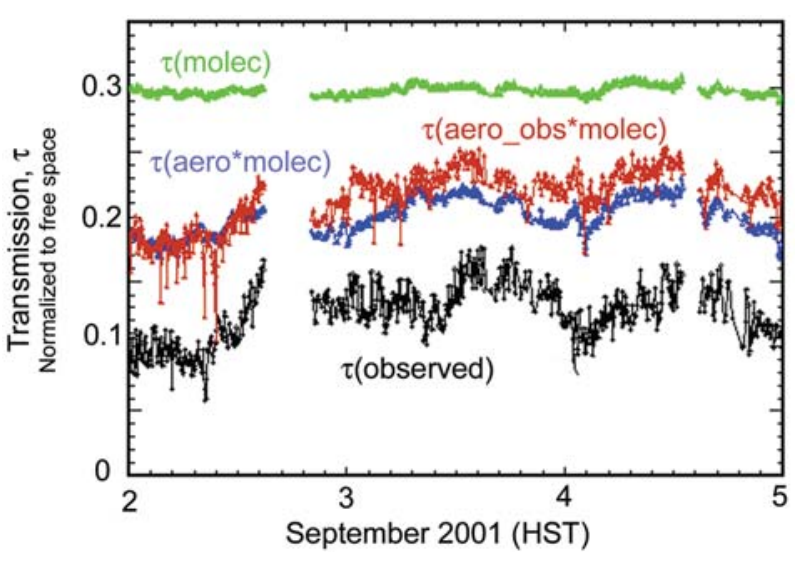

FIG. I 2. IR transmittance for 2-5 Sep 200I. The measured transmittance (black line) is about $62 \%$ of the modeled (red and blue lines) and about I/3 of the transmittance predicted using molecular absorption only (green line).

near-surface bubble generation, particle size distributions, laser probing of the atmosphere, and sources for both microwave and IR signals. In all, more than 25 researchers from four countries, six universities, and four government agencies were directly involved with the RED experiment.

Through meteorological and propagation measurements, the RED experiment achieved a number of its objectives. First, although we did not experience the desired conditions of simultaneous high seas, high winds, and large surface gradients of temperature and 
humidity, necessary to significantly affect the evaporation duct, observations verify that waves do modify the scalars within the air-sea surface layer. Second, an intriguing and controversial result is the lack of agreement of the scalar profile constants with those typically observed over land. To date no experimental error has been found to account for these deviations, and we are continuing to investigate the matter. Finally, as expected for the conditions encountered during RED (trade wind, moderate seas, unstable), we show that MOS theory combined with high-quality meteorological measurements can be used by propagation models to accurately predict microwave signal levels. Compared to propagation at a wavelength of $3 \mathrm{~cm}$ through a standard atmosphere, the evaporation-ducting conditions during RED increased the average received signal level by a factor of 1000 . The impact of meteorology on propagation over the sea is clearly significant. Achieving signal gain of this magnitude in hardware is extremely expensive. Meteorology gives us this gain for free.

We hope to inspire additional research and we encourage our colleagues to formulate air-sea interaction experiments, make these very difficult measurements, and increase our understanding of this most important boundary.

ACKNOWLEDGMENTS. The RED experiment was supported by Code 322MM of the Office of Naval Research.

\section{REFERENCES}

Ament, W. D., 1953: Toward a theory of reflection by a rough surface. Proc. IRE, 41, 142-146.

Anderson, K. D., S. Doss-Hammel, and P. Frederickson, 2003: Microwave and infrared propagation over the sea during the Rough Evaporation Duct (RED) experiment. Preprints, Military Communications: Conf., Boston, MA, IEEE, 1416-1421.

Barrios, A. E., 1992: Parabolic equation modeling in horizontally inhomogeneous environments. IEEE Trans. Antennas Propag., 40, 791-797.

Bean, B. R., and E. J. Dutton, 1966: Radio Meteorology. NBS Monogr., Vol. 92, National Bureau of Standards, $435 \mathrm{pp}$.

Berk, A., and Coauthors, 1999: MODTRAN4 version 2 user's manual. Air Force Research Laboratory, Space Vehicles Directorate, 102 pp.

Booker, H. G., 1948: Some problems in radio meteorology. Quart. J. Roy. Meteor. Soc., 74, 277-285.

Businger, J. A., J. C. Wyngaard, Y. Izumi, and E. F. Bradley, 1971: Flux-profile relationships in the atmospheric surface layer. J. Atmos. Sci., 28, 181-189.
Clarke, A., V. Kapustin, S. Howell, and K. Moore, 2003: The contribution of coastal aerosol from breaking waves to visible and IR light-extinction over a $10 \mathrm{~km}$ optical path during RED. Preprints, 12th Conf. on Interactions of the Sea and Atmosphere, Long Beach, CA, Amer. Meteor. Soc., CD-ROM, 6.3.

Crahan, K. K., D. Hegg, D. Covert, and H. Johnson, 2003: Speciation of organic aerosol and their relationship to light scattering during RED. Preprints, 12th Conf. on Interactions of the Sea and Atmosphere, Long Beach, CA, Amer. Meteor. Soc., CD-ROM, 9.9.

Davidson, K. L., P. Guest, D. L. Mabey, P. A. Frederickson, and K. D. Anderson, 2003: The use of kite observations to study air-sea interaction-controlled atmospheric surface layer profiles during the RED experiment. Preprints, 12th Conf. on Interactions of the Sea and Atmosphere, Long Beach, CA, Amer. Meteor. Soc., CD-ROM, 6.1.

De Leeuw, G., M. Moerman, L. Cohen, B. Brooks, M. Smith, and E. Vignati, 2003: Aerosols, bubbles and sea spray production studies during the RED experiment. Preprints, 12th Conf. on Interactions of the Sea and Atmosphere, Long Beach, CA, Amer. Meteor. Soc., CD-ROM, 9.6.

Edlen, B., 1966: The refractive index of air. Meteorologia, 2, 71-80.

Fairall, C. W., E. F. Bradley, D. P. Rogers, J. B. Edson, and G. S. Young, 1996: Bulk parameterization of airsea fluxes for the Tropical Ocean-Global Atmosphere Coupled Ocean-Atmosphere Response Experiment. J. Geophys. Res., 101, 3747-3764.

Frederickson, P., K. Davidson, K. Anderson, S. DossHammel, and D. Tsintikidis, 2003: Air-sea interaction processes observed from buoy and propagation measurements during the RED experiment. Preprints, 12th Conf. on Interactions of the Sea and Atmosphere, Long Beach, CA, Amer. Meteor. Soc., CDROM, 9.3.

Freehafer, J. E., 1951a: Tropospheric refraction. Propagation of Short Radio Waves, D. E. Kerr, Ed., McGraw-Hill, 9-22.

— , 1951b: Geometrical optics. Propagation of Short Radio Waves, D. E. Kerr, Ed., McGraw-Hill, 41-58.

Friehe, C. A., and T. Hristov, 2003: Flux-profile relations over the open ocean. Preprints, 12th Conf. on Interactions of the Sea and Atmosphere, Long Beach, CA, Amer. Meteor. Soc., CD-ROM, 6.7.

Hitney, H. V., J. H. Richter, R. A. Pappert, K. D. Anderson, and G. B. Baumgartner, 1985: Tropospheric radio propagation assessment. Proc. IEEE, 73, 265-283.

Hristov, T., and C. Friehe, 2003: EM propagation over the ocean: Analysis of RED experiment data. Preprints, 12th Conf. on Interactions of the Sea and 
Atmosphere, Long Beach, CA, Amer. Meteor. Soc., CD-ROM, 9.2.

$\longrightarrow,-$, air flow over ocean waves: Identification of cooperative behavior buried in turbulence. Phys. Rev. Lett., 81, 5245-5248.

_, S. Miller, and C. Friehe, 2003: Dynamical coupling of wind and ocean waves through wave-induced air flow. Nature, 422, 55-58.

Jeske, H., 1971: The state of radar range prediction over the sea. Tropospheric Radio Wave Propagation-Part II, NATO-AGARD Proc. AD719714, 50-1-50-10.

Katzin, M., R. W. Bauchman, and W. Binnian, 1947: 3and 9-centimeter propagation in low ocean ducts. Proc. IRE, 35, 891-905.

Kerr, D. E., 1951: Propagation of Short Radio Waves. McGraw-Hill, 728 pp.

Khelif, D., S. P. Burns, and C. A. Friehe, 1999: Improved wind measurements on research aircraft. J. Atmos. Oceanic Technol., 16, 860-875.

Levy, M., 2000: Parabolic Equation Methods for Electromagnetic Propagation. Institution of Electrical Engineers, $336 \mathrm{pp}$.

Liebe, H., 1985: An updated model for millimeter wave propagation in moist air. Radio Sci., 20, 1069-1089.

Miles, J. W., 1957: On the generation of surface waves by shear flows. J. Fluid Mech., 3, 185-204.

Nilsson, E. D., M. Martensson, S. van Ekeren, G. de Leeuw, M. Moerman, C. O’Dowd, R. Flanagan, and M. Geever, 2003: Eddy correlation measurements of the primary marine aerosol source. Preprints, 12th Conf. on Interactions of the Sea and Atmosphere, Long Beach, CA, Amer. Meteor. Soc., CD-ROM, 6.8.

Obukhov, A. M., 1971: Turbulence in an atmosphere with non-uniform temperature. Bound.-Layer Meteor., 2, 7-29.

Oncley, S. P., C. A. Friehe, J. C. LaRue, J. A. Businger, E. C. Itsweire, and S. Chang, 1996: Surface-layer fluxes, profiles, and turbulence measurements over uniform terrain under near-neutral conditions. J. Atmos. Sci., 53, 1029-1044.

Pekeris, C. L., 1946: Accuracy of the earth-flattening approximation in the theory of microwave propagation. Phys. Rev., 70, 518-522.

Phillips, O. M., 1966: The Dynamics of the Upper Ocean. Cambridge University Press, 336 pp.

Reid, J. S., B. Brooks, H. H. Jonsson, T. Hirstov, K. D. Anderson, and E. A. Reid, 2003: Evaluation of coarse mode sea-salt flux parameterizations through shipboard eddy-correlation methods coupled with vertical profile data. Preprints, 12th Conf. on Interactions of the Sea and Atmosphere, Long Beach, CA, Amer. Meteor. Soc. CD-ROM, 9.4.

Richter, J. H., and H. V. Hitney, 1988: Antenna heights for the optimum utilization of the oceanic evaporation duct. SSC San Diego Tech. Doc. 1209, Vol. 1, $222 \mathrm{pp}$.

Richter, J. H., and H. V. Hitney, 1988: Antenna heights for the optimum utilization of the oceanic evaporation duct. SSC San Diego Tech. Doc. 1209, Vol. 2, $291 \mathrm{pp}$.

The Physical Society, 1946: Meteorological factors in radio-wave propagation. The Physical Society Rep. of Conf. held on 8 April 1946 at the Royal Institution, London, 343 pp.

Tsintikidis, D., S. Doss-Hammel, P. Frederickson, and K. Davidson, 2003: Infrared propagation in the marine atmospheric surface layer: Extinction and refraction. Preprints, 12th Conf. on Interactions of the Sea and Atmosphere, Long Beach, CA, Amer. Meteor. Soc., CD-ROM, 9.8.

van Eijk, A. M. J., L. H. Cohen, L. J. Navarro, and G. de Leeuw, 2002: Near-surface aerosol transmission in the marine environment. Proc. SPIE Ninth Int. Symp. on Remote Sensing, Crete, Greece, International Society for Optical Engineering, 160-165. 